\title{
Predictors of Exam Cheating Among the High School Students: Role of Personality Characteristics, Sensation-Seeking, Locus of Control and Exam Anxiety
}

\author{
Nasser Behroozi ${ }^{1 *}$, Zahra Rafiee ${ }^{2}$, Alireza Haji Yakhchali ${ }^{3}$ \\ 1. Associate professor, Shahid Chamran University, Ahvaz, Iran \\ 2. MA student of Psychology, Shahid Chamran University, Ahvaz, Iran \\ 3. Assistant professor, Shahid Chamran University, Ahvaz, Iran \\ *Corresponding author: behroozyn@yahoo.com
}

\begin{abstract}
The research purpose is to evaluate the personality characteristics, sensation-seeking, a locus of control and exam anxiety as the predictors of exam cheating among the high school students in Ahvaz City. Hence, the research employed a correlation and predictive method. The sample comprised 79 students with cheating background and 78 students without cheating background in the high schools of Ahvaz City. The selection of the cheating group was done with the confirmation and agreement of at least three teachers in each class and the non-cheating students were also randomly selected from the same class. The employed tools included Zukerman scale of sensation-seeking, Nowicki-Strickland Scale of locus of control and Friedman test anxiety scale. The data were analyzed using the discriminant analysis method. The obtained results indicated that the linear combination of the research variables can predict students' cheating in the exams in the high schools located in Ahvaz City. Moreover, findings indicated that sensationseeking and consciousness are the predictors of high school student's cheating.
\end{abstract}

Keywords: cheating in an exam, personality characteristics, sensation-seeking, locus of control, exam anxiety.

\section{Introduction}

One of the most important and common problems in all the levels of education is the phenomenon of scientific fraud. Unfortunately, educational systems have borne enormous expenses for that. Due to the connection between this phenomenon and the modern communication technologies and also the increasing role of education in the social status, this phenomenon has continuously undergone drastic change and evolution. On the other hand, academic dishonesty is endemic in all the levels of education in both industrialized and developing countries. Studies carried out in other countries indicate that cheating has increased during the recent years and has amounted to 60 percent. The subject of cheating has not received an adequate amount of attention and the negative consequences of this negligence and the lack of knowledge of academic misconduct will arise in the near future (Ballantine, Larres, \& Mulgrew, 2014). Cheating negatively impacts the educational factors and the students are most affected by that; for example, the students may come to this conclusion that, those who cheat are more successful. This attitude without any accurate logic demoralizes them and if not controlled may trigger a sense of injustice in them (Ballantine et al., 2014). Moreover, studies show that, there is a close relationship between cheating in schools and professional behavior at the work environment. In fact, this shows that, the negative consequences of cheating continue to exist

To cite this paper:Behroozi, N., Rafiee, Z., \&Haji Yakhchali, A.(2019). Predictors of Exam Cheating Among the High School Students: Role of Personality Characteristics, Sensation-Seeking, Locus of Control and Exam Anxiety. Iranian Evolutionary and Educational Psychology Journal, 1, 1, 24-33. 
until the future and therefore, this phenomenon should be prevented in its early stages and this can be done by full recognition of academic dishonesty and factors affecting it.

Academic misconduct or scientific fraud has different kinds, which includes:

1. Scientific fabrication that is the falsification of data or research and is considered as the most severe type of academic misconduct (Gross, 2016).

2. Plagiarism that is the adoption of original creations of other authors without due acknowledgement (Gross, 2016).

3. Duplication that is to report the results of other individuals' results with exact wording and without direct citation or due acknowledgement (Gross, 2016).

4. Academic fraud and misuse of scientific titles

5. The use of unknown educational certificates

6. Cheating on academic and scientific tests and exams

One of the most important types of academic misconduct or fraud is cheating in exams. The method of taking tests influences students' methods of learning and their interest in learning. Indeed, students are eager to know why and to what degree they have learned and teachers tend to get to know about the quality and quantity of their students' academic achievement. An exam is a criterion to assess and improve the education; however, there exist some problems while taking and administering tests and exams, one of which is exam cheating that bothers the school staff and considerable amount of energy is needed to make sure of the accurate administration of the exams at schools. Despite careful invigilating, some students even use the minimum possibilities to cheat on their exams. In fact, exam cheating is one of the destructive factors of educational centers' evaluation systems that undermine their authority and exerts negative psychological effects on adolescents.

In the regulation of preventing fraud and misconduct in post-graduate entrance tests, cheating has been defined as: using any tools to obtain exam-related information from inside or outside the exam session while taking examination by the participants in different stages of exam and or any kind of method that leads to illegal acquirement of the exam-related information and the deceit of the examiners (Marusic, Wager, Utrobicic, Rothstein, \& Sambunjak, 2016).

As stated on the subject of cheating, there are different factors related to cheating, one of which is personality characteristics. Personality characteristics are constant traits that do not change from one situation or condition to another. They are stable and durable responding to different stimuli in an identical manner and can be the predictors of individual's behavior in different situations (Schultz \& Schultz, 2016).

These traits can make the individual susceptible to some behaviors like cheating. Most studies have tested out the individual differences as the predictor of educational cheating. However, important personality characteristics have drawn less attention (Paulhus \& Dubois, 2015). These five factors are: extroversion, agreeableness, openness, neuroticism and conscientiousness (Costa \& McCrae, 1992). Costa and McCrae (1992) employed factor analysis and concluded that five big factors can be regarded as individual differences in personality characteristics. Some researchers contend that, personality characteristics are factors that lead to the students' decision making for demonstrating cheating behavior (Haines, Diekhoff, E., \& 
Clark, 1986) (Anderman \& Koenka, 2017). In one study done by Giluk and Postlethwaite (2015), five big factors of personality are significantly correlated with the reports of academic fraud.

Another feature that is related to cheating is sensation-seeking. Zuckerman (2014) defines sensation-seeking as a trait that seeks for new, complex, varied and fresh experience and it is the tendency to get involved with physical, social and financial risks. He considers sensation-seeking to have four aspects of risk-taking, experience seeking, disinhibiting and border seeking (Zuckerman, 2014). On one hand, sensation-seeking is conceptually and experimentally related to risk-taking behavior and on the other hand, pleasures and arousal of emotion in risk-taking decisions are associated with deviant behavior (DeAndrea, Carpenter, Shulman, \& Levine, 2009). Many studies have confirmed the relationship between sensation-seeking, delinquency, and crimes. Moreover, individuals with low self-control or high impulsivity demonstrate deviant behaviors because this trait can help them in easy access to the resources or documents (DeAndrea et al., 2009). Hence, sensation-seeking can have a significant relationship with cheating as a deviant behavior. In a study done by Jensen, Arnett, Feldman, and Cauffman (2002), acceptance of cheating and cheating behavior had a significant and positive relationship with a tolerance of deviance and significant, negative relationship with self-restraint. Moreover, DeAndrea et al. (2009) ound sensation-seeking as the predictor of cheating. On the other hand, the perception that individuals have from the causality of the results can play a significant role in cheating behavior.

Locus of control refers to the individuals' belief on how to control the environment. According to Rotter, locus of control is a set of beliefs based on which the individual evaluates his/her success or failure in terms of the abilities and weaknesses (Ajzen, 2002). Moreover, Rotter (1966) contends that, individuals are characterized into two groups regarding their beliefs about locus of control.

1. A group that attributes their success and failure to themselves.

2. A group that attributes their success and failure to their surrounding environment and espouses this belief that the events are determined by chance, others' power, unknown and inevitable factors and the results of each action is beyond personal control (Rotter, 1966).

In most studies done in this realm, it has been found that individuals who have an internal locus of control have better educational performance as compared to individuals with external locus of control (Ajzen, 2002). Therefore, students with the external locus of control are more probable to resort to cheating behaviors. Houston (1977) in another research concluded that, cheating is correlated with the subscale of (easy-difficult) from the scale of Rotter.

In another research by Karabenick and Srull (1978), the interactive effect between personality and locus of control was evaluated. In this research, when the subjects with internal self-control were told that the assignment needs skill, they were more probable to cheat. Moreover, the subjects with external self-control cheated more when the luck and chance were determinants of performance. Boshoff and Van Zyl (2011) carried out a study on the staff working in the financial sector of South Africa and concluded that, the internal locus of control and autonomy have a significant and positive relationship with ethical behavior. On the contrary, the external locus of control (insignificant self-control) has significant and negative relationship with ethical behavior. 
Another factor which might be correlated with cheating is test anxiety. Exam anxiety is a conditional anxiety that is strongly associated with students' educational performance and achievement (Pintrich \& De Groot, 1990). Exam anxiety is a form of state or situational anxiety which includes three factors: psychological factor (thought) such as exam-related inaccurate thoughts and concerns, behavioral factor such as inattention to or distraction from the assignment and emotional and psychological factor such as autonomous reactions based on psychosomatic symptoms of anxiety (Stöber, 2004). Cassady and Johnson (2002) in another research, found a negative correlation between exam anxiety and educational performance.

In fact, individuals with high levels of anxiety get involved with irrelevant activities and such behaviors harm or impair the educational performance and therefore, it's possible that the individual cheats on the exam due to the pressures of parents' and educational system's expectations. Shelton and Hill (1969) in a study found support for the positive relationship between exam anxiety and cheating. Shelton and Hill (1969) concluded that, there is significant correlation between 30 seconds of exam anxiety and cheating. In another research by Wowra (2007) on a sample of American college students, an insignificant positive relationship was found between exam cheating and exam anxiety symptoms.

\section{Research hypotheses}

1. The trait of neuroticism can predict high school students' exam cheating.

2. The trait of extroversion can predict high school students' exam cheating.

3. The trait of openness to experience can predict high school students' exam cheating.

4. The trait of agreeableness can predict high school students' exam cheating.

5. The trait of conscientiousness can predict high school students' exam cheating.

6. The trait of sensation-seeking can predict high school students' exam cheating.

7. The trait of internal locus of control can predict high school students' exam cheating.

8. The trait of external locus of control can predict high school students' exam cheating.

9. The trait of exam anxiety can predict high school students' exam cheating.

10. The linear combination of personality traits, sensation-seeking, locus of control and exam cheating can predict high school students' exam cheating.

\section{Material and Methods}

\section{Statistical society, sample and sampling}

The present research employed a correlational and predictive method. The statistical society included all the high school students of Ahvaz City in the school year of 2013-2014. The research sample included 200 individuals, 100 cheating, and 100 non-cheating students. A sample of 50 cheating students and a sample of 50 non-cheating students were selected from boy's schools. The same sampling was carried out at the girl's school. Teachers were interviewed for the selection of cheating students. First, four classes were randomly selected from each school and then, 5 teachers were interviewed for the identification of cheating students. Cheating students were selected provided that, three teachers were in agreement of their academic misconduct. Non-cheating students (at least 4 students for each class) were also selected. The two groups filled out the research questionnaires. All the administered questionnaires amounted to 200 and 32 questionnaires were eliminated due to the incomplete 
answers. The data analysis was done on 168 questionnaires. The sample size in accordance to the gender, being cheating or non-cheating is as follows:

Table 1.Frequency of the research participants

\begin{tabular}{|c|c|c|c|}
\hline Variables & Boys & Girls & Total \\
\hline cheating & 38 & 41 & 79 \\
\hline Non-cheating (Normal) & 39 & 43 & 82 \\
\hline
\end{tabular}

\section{The research tools}

Revised NEO Personality Inventory: This questionnaire was first designed by Costa and McCrae in 1985 and had 185 questions. After that, based on this old version, the 60-item and 240-item questionnaire were designed and developed. The 60-item Revised NEO Personality Inventory that evaluates five big factors of neuroticism, openness to experience, agreeableness, extroversion and conscientiousness was used in the present research and each of the factors entailed 12 questions. In the present research, the reliability coefficient of this questionnaire using Cronbach's alpha for five factors of neuroticism, openness to experience, extroversion, agreeableness and conscientiousness were equal to .49, .65, .63, .73 and .82, respectively. Moreover, the reliability using bisection equaled $.29, .43, .41, .52$ and .59 .

Sensation-seeking questionnaire: This short-form scale (15 items) evaluates sensationseeking and was designed and developed by Zuckerman (2014). This questionnaire is objectively scored on a 2-point scale of Yes and No. The reliability of this questionnaire using Cronbach's alpha and bisection were equal to .57 and .46 , respectively. The criterion validity was used to assess the validity. As the result, the questions of 4, 6 and 7 were omitted because they were not significant at the level of .05.

Nowicki-Strickland Scale of locus of control: Nowicki-Strickland Scale (Nowicki \& Strickland, 1973) of locus of control was developed in 1973 and was used in this research. This paper-and-pencil questionnaire was translated by Boroumand Nasab and Najjariyan (1994) in the educational and psychology department of Shahid Chamran University. This 40-item questionnaire is scored on a 2-point scale of Yes and No by the scores of zero and one. The reliability of the questionnaire using Cronbach alpha and bisection was equal to .59 and .47, respectively. The criterion validity was used to evaluate the validity of the scale and therefore, the questions of $4,12,20,22,23,24$ and 35 were omitted because they were not significant at .5 .

Test of examination anxiety Friedman: This questionnaire was designed and developed by Friedman and Bendas-Jacob (1997) to evaluate the adults' exam anxiety. This 23-item questionnaire has 3 components including social humiliation (items of 1 to 8), cognitive error (items of 9 to 17) and stress (items of 18 to 23). This questionnaire is scored on a 4-point Likert scale and has 23 items. In the present research, the validity was confirmed by confirmatory factor analysis and the items $(9,10,13,16$ and 23) with load factor less than .3 were omitted.

\section{Results}

In this section, the descriptive statistics of the research variables have been presented. Table 2 shows the descriptive statistics of the research variable. This table shows the mean, standard deviation, minimum and maximum of the predictor variables for cheating and non-cheating students. 
With regard to the table 3 and the significance level of $F$ statistics, from among the predictor variables, only two variables of sensation-seeking and conscientiousness are significant (significant level for these two variables were less than .05). As observed, the value of WilksLambda for these two variables is smaller while the F statistics are bigger and more significant which indicate the significance of these two variables. This significance shows that cheating and non-cheating students were well distinguished in two variables of sensation-seeking and conscientiousness. For want of another word, the two cheating and non-cheating groups were significantly different in sensation-seeking and conscientiousness. Other predictor variables were not significant at the significance level of .05.

Table 2. Mean and Standard Deviation of the Predictor Variables for Cheating and Non-Cheating Groups

\begin{tabular}{|c|c|c|c|c|c|c|c|c|}
\hline \multirow{2}{*}{ Predictor Variables } & \multicolumn{4}{|c|}{ Cheating Group } & \multicolumn{4}{c|}{ Non-Cheating Group } \\
\cline { 2 - 9 } & Mean & Sd & Min & Max & Mean & Sd & Min & Max \\
\hline Neuroticism & 31.4 & 6.6 & 10 & 48 & 30.6 & 6.1 & 14 & 42 \\
\hline Extroversion & 38.9 & 4 & 28 & 50 & 38.4 & 4.6 & 26 & 47 \\
\hline Openness to Experience & 28.9 & 3.3 & 23 & 36 & 29.7 & 3.6 & 20 & 39 \\
\hline Agreeableness & 35.7 & 5.7 & 22 & 47 & 37 & 5.3 & 22 & 50 \\
\hline Conscientiousness & 43.5 & 6.9 & 30 & 56 & 46.6 & 6.2 & 33 & 60 \\
\hline Sensation-Seeking & 7.2 & 2.2 & 2 & 10 & 6.3 & 1.9 & 1 & 8 \\
\hline Internal Locus Of Control & 11.7 & 4.5 & 5 & 20 & 10.9 & 3.9 & 4 & 19 \\
\hline External Locus Of Control & 23.3 & 2.4 & 21 & 35 & 21 & 2.5 & 21 & 21 \\
\hline Exam Anxiety & 33.7 & 11.8 & 2 & 51 & 30.2 & 11.1 & 3 & 49 \\
\hline
\end{tabular}

Table 3.Test of groups' equality of means (cheating and non-cheating students)

\begin{tabular}{|c|c|c|c|c|c|}
\hline Predictor Variables & Wilks Lambda & Statistics F & Df 1 & Df 2 & Sig. \\
\hline Neuroticism & .999 & .121 & 1 & 117 & .729 \\
\hline Extroversion & .989 & 1.252 & 1 & 117 & .266 \\
\hline Openness To Experience & .988 & 1.388 & 1 & 117 & .241 \\
\hline Agreeableness & .996 & .458 & 1 & 117 & .500 \\
\hline Conscientiousness & .957 & 5.273 & 1 & 117 & .023 \\
\hline Sensation-Seeking & .948 & 6.477 & 1 & 117 & .012 \\
\hline Internal Locus Of Control & .990 & 1.200 & 1 & 117 & .276 \\
\hline External Locus Of Control & .957 & .420 & 1 & 117 & .501 \\
\hline Exam Anxiety & .977 & 2.813 & 1 & 117 & .096 \\
\hline
\end{tabular}

It can be concluded that, cheating and non-cheating students do not have a significant relationship with other variables. Therefore, the fifth and sixth hypotheses are confirmed and other hypotheses are rejected. Here, two other methods (audit functions and means' equality test) are used to test out the hypotheses and the results are presented in table 4 . With regard to the significance level of audit functions, the variables of sensation-seeking and conscientiousness were selected because only these two functions are significant that indicates that, only these two variable have acceptable distinguishing power to explain the dependent variable. Therefore, the fifth and sixth hypotheses are confirmed and other hypotheses are rejected. The results of table 5 are related to the tenth hypothesis (combinative hypothesis). 
As observed in table 5, given the insignificance level of Lambda-Wilks and significance level of chi-square, it can be concluded that the obtained audit function has good distinguishing power to explain the dependent variables (cheating and non-cheating groups). Therefore, the tenth hypothesis is confirmed and the linear combination of personality traits, sensation-seeking, a locus of control and exam cheating can predict high school students' exam cheating.

Table 4. The summary of the data related to the audit function of the predictor variables

\begin{tabular}{|c|c|c|c|c|c|c|c|}
\hline Predictor variables & $\begin{array}{l}\text { Eigen } \\
\text { value }\end{array}$ & $\begin{array}{l}\text { Variance } \\
\text { percent }\end{array}$ & $\begin{array}{l}\text { Canonical } \\
\text { correlation }\end{array}$ & $\begin{array}{c}\text { Fixed } \\
\text { ratio }\end{array}$ & $\begin{array}{l}\text { Prediction of } \\
\text { group } \\
\text { membership }\end{array}$ & $\begin{array}{c}\text { Kappa } \\
\text { coefficient }\end{array}$ & $\begin{array}{c}\text { Significance } \\
\text { of kappa }\end{array}$ \\
\hline neuroticism & .02 & 100 & .049 & -4.78 & 50.7 & .05 & .48 \\
\hline extroversion & .002 & 100 & .047 & -8.89 & 51.3 & .06 & .37 \\
\hline $\begin{array}{l}\text { Openness to } \\
\text { experience }\end{array}$ & .009 & 100 & .096 & -8.45 & 51 & .07 & .39 \\
\hline agreeableness & .014 & 100 & .118 & -6.54 & 52.7 & .11 & .15 \\
\hline conscientiousness & .072 & 100 & .259 & $7.24-$ & 57.8 & .16 & .05 \\
\hline Sensation-seeking & .049 & 100 & .217 & -3.06 & 59 & .19 & .01 \\
\hline $\begin{array}{c}\text { Internal locus of } \\
\text { control }\end{array}$ & .012 & 100 & .111 & -2.73 & 55.6 & .17 & .57 \\
\hline $\begin{array}{c}\text { External locus of } \\
\text { control }\end{array}$ & .076 & 100 & .270 & -1.04 & 58.8 & .08 & .28 \\
\hline Exam anxiety & .017 & 100 & .129 & $2.61-$ & 50.9 & .12 & .09 \\
\hline
\end{tabular}

Table 5.Summary of audit functions using concurrent analysis ( 9 predictor variables) and step-wise analysis (2 predictor variables)

\begin{tabular}{|c|c|c|}
\hline information on audit function & Concurrent analysis & Step-wise analysis \\
\hline Number of functions & 1 & .091 \\
\hline Eigen value & .14 & 100 \\
\hline Variance percent & 100 & 100 \\
\hline Summative percent & 100 & .29 \\
\hline Canonical correlation & .35 & .1 \\
\hline Eta Square & .12 & .92 \\
\hline Wilks Lambda & .87 & 20.14 \\
\hline Chi-square & 15.37 & .01 \\
\hline Degrees of freedom & 8 & 61.5 \\
\hline Significance of audit function & .03 & .51 \\
\hline Prediction of group membership & 61.7 & .03 \\
\hline
\end{tabular}

\section{Discussion}

In this research, seven hypotheses were not confirmed. It can be mentioned that cheating is a variable that is influenced by a large number of factors from personal and psychological factors to familial and educational factors. It's obvious that such factors may not be able to predict cheating in a specific period of time or a particular culture. The impact of personality on cheating is very complicated. In the present research, four big personality traits including neuroticism, 
extroversion, agreeableness and openness to experience can't predict exam cheating and only conscientiousness is the predictor of cheating. These results are in line with the results of the studies by Nathanson, Paulhus, and Williams (2006) and Williams, Nathanson, and Paulhus (2010) However, in the research by Williams et al. (2010), the conscientiousness and agreeableness could predict cheating.

Bolin (2004) asserts that, attitude toward cheating is the mediator between the personality traits and cheating. Therefore, it can be mentioned that perhaps, personality traits do not directly affect cheating. In the present research, the relationship between personality traits and cheating was investigated and only the aspect of conscientiousness could predict the exam cheating. Individuals who had higher levels of conscientiousness were less likely to cheat. Students, who are more conscientious, need more success, feel more responsible and show more efforts. Based on this, such individuals are less likely to consider cheating as a means to achieve their goals.

Another variable that could predict cheating is sensation-seeking (sixth hypothesis). This finding is in line with the results of the research by Murdock and Anderman (2006), Kisamore, Stone, and Jawahar (2007) and DeAndrea et al. (2009). In many studies, it was concluded that, individuals with high levels of sensation-seeking tend to get involved in a high-risk task to increase their level of arousal. Probably, low levels of arousal cause the individuals to have less degree of fear. Such people look for stimulations to increase their level of arousal. Cheating is a high-risk and punishment-prone behavior which somehow seems to be frightening. Therefore, it can be expected that, students who have higher levels of sensation-seeking are more probable to demonstrate high-risk behaviors. Moreover, based on the previous studies, it has been found out that sensation-seeking during the adolescence has significant relationship with delinquency. Delinquency is a behavior against the law and it can be expected that cheating as a deviant behavior is associated with sensation-seeking.

The seventh and eighth hypotheses for the locus of the control in the prediction of cheating in high school students were not proved. Put it differently, no significant relationship was observed between the cheating and non-cheating students in terms of internal and external locus of control. This finding was in harmony with the results of the research carried out by Houston (1977) and Leming (1980), and not in line with the results of the studies by Karabenick and Srull (1978), Crown and Spiller (1998), Alarape and Onakoya (2003) and Boshoff and Van Zyl (2011). Based on the findings of Karabenick and Srull (1978), when the subjects with internal self-control were told that the assignment needs skill, they were more probable to cheat. Moreover, the subjects with external self-control cheated more when the luck and chance were determinants of performance. Students in testing situations do not have a clear perception of the reasons for their performance and this causes the locus of control not be able to predict exam cheating.

The ninth hypothesis which put forward this idea that, the trait of exam anxiety can predict high school students' exam cheating was not supported. As stated, cheating is one of the variables that is influenced by a large number of factors which might change in accordance to the culture and different time periods. Therefore, it can be expected that some factors such as exam anxiety and locus of control cannot predict the exam cheating. The obtained results from the statistical analysis confirmed the tenth hypothesis that the linear combination of personality traits, sensation-seeking, locus of control and exam cheating can predict high school students' 
exam cheating. Cheating students in comparison with non-cheating students obtain higher scores in the variables of extroversion, neuroticism,, sensation-seeking, internal locus of control, external locus of control and exam anxiety. Moreover, they obtained lower score on the variables of openness to experience, agreeableness, and conscientiousness. The results demonstrate that, more significant difference between personality traits, sensation-seeking, locus of control and exam anxiety can better predict the possibility of exam cheating in high school students.

\section{References}

Ajzen, I. (2002). Perceived behavioral control, self-efficacy, locus of control, and the theory of planned behavior. Journal of applied social psychology, 32(4), 665-683.

Alarape, A., \& Onakoya, A. (2003). Correlates of examination cheating behaviour among university students. IFE Psychologia: An International Journal, 11(1), 71-79.

Anderman, E. M., \& Koenka, A. C. (2017). The Relation Between Academic Motivation and Cheating. Theory Into Practice, 56(2), 95-102.

Ballantine, J., Larres, P. M., \& Mulgrew, M. (2014). Determinants of academic cheating behavior: The future for accountancy in Ireland. Paper presented at the Accounting Forum.

Bolin, A. U. (2004). Self-control, perceived opportunity, and attitudes as predictors of academic dishonesty. The Journal of Psychology, 138(2), 101-114.

Boshoff, E., \& Van Zyl, E. (2011). The relationship between locus of control and ethical behaviour among employees in the financial sector. Koers, 76(2), 283-303.

Cassady, J. C., \& Johnson, R. E. (2002). Cognitive test anxiety and academic performance. Contemporary Educational Psychology, 27(2), 270-295.

Costa, P., \& McCrae, R. R. (1992). Four ways five factors are basic. Personality and Individual Differences, 13(6), 653-665.

Crown, D. F., \& Spiller, M. S. (1998). Learning from the literature on collegiate cheating: A review of empirical research. Journal of Business Ethics, 17(6), 683-700.

DeAndrea, D. C., Carpenter, C., Shulman, H., \& Levine, T. R. (2009). The relationship between cheating behavior and sensation-seeking. Personality and Individual Differences, 47(8), 944947.

Friedman, I. A., \& Bendas-Jacob, O. (1997). Measuring perceived test anxiety in adolescents: A self-report scale. Educational and Psychological Measurement, 57(6), 1035-1046.

Giluk, T. L., \& Postlethwaite, B. E. (2015). Big Five personality and academic dishonesty: A meta-analytic review. Personality and Individual Differences, 72, 59-67.

Gross, C. (2016). Scientific misconduct. Annual review of psychology, 67, 693-711.

Haines, V. J., Diekhoff, G. M., E., L. E., \& Clark, R. E. (1986). College cheating: Immaturity, lack of commitment, and the neutralizing attitude. Research in Higher Education, 25, 342354.

Houston, J. P. (1977). Cheating behavior, anticipated success-failure, confidence, and test importance. Journal of educational psychology, 69(1), 55.

Jensen, L. A., Arnett, J. J., Feldman, S. S., \& Cauffman, E. (2002). It's wrong, but everybody does it: Academic dishonesty among high school and college students. Contemporary Educational Psychology, 27(2), 209-228. 
Karabenick, S. A., \& Srull, T. K. (1978). Effects of personality and situational variation in locus of control on cheating: Determinants of the "congruence effect". Journal of personality, 46(1), 72-95.

Kisamore, J. L., Stone, T. H., \& Jawahar, I. (2007). Academic integrity: The relationship between individual and situational factors on misconduct contemplations. Journal of Business Ethics, 75(4), 381-394.

Leming, J. S. (1980). Cheating behavior, subject variables, and components of the internalexternal scale under high and low risk conditions. The Journal of Educational Research, 74(2), 83-87.

Marusic, A., Wager, E., Utrobicic, A., Rothstein, H., \& Sambunjak, D. (2016). Interventions to prevent misconduct and pro-mote integrity in research and publication. status and date: New, published in(4).

Murdock, T. B., \& Anderman, E. M. (2006). Motivational perspectives on student cheating: Toward an integrated model of academic dishonesty. Educational Psychologist, 41(3), 129145.

Nathanson, C., Paulhus, D. L., \& Williams, K. M. (2006). Predictors of a behavioral measure of scholastic cheating: Personality and competence but not demographics. Contemporary Educational Psychology, 31(1), 97-122.

Nowicki, S., \& Strickland, B. R. (1973). A locus of control scale for children. Journal of consulting and clinical psychology, 40(1), 148.

Paulhus, D. L., \& Dubois, P. J. (2015). The link between cognitive ability and scholastic cheating: A meta-analysis: Educational Publishing Foundation.

Pintrich, P. R., \& De Groot, E. V. (1990). Motivational and self-regulated learning components of classroom academic performance. Journal of educational psychology, 82(1), 33.

Rotter, J. B. (1966). Generalized expectancies for internal versus external control of reinforcement. Psychological monographs: General and applied, 80(1), 1.

Schultz, D. P., \& Schultz, S. E. (2016). Theories of personality: Cengage Learning.

Shelton, J., \& Hill, J. P. (1969). Effects on cheating of achievement anxiety and knowledge of peer performance. Developmental Psychology, 1(5), 449.

Stöber, J. (2004). Dimensions of test anxiety: Relations to ways of coping with pre-exam anxiety and uncertainty. Anxiety, Stress \& Coping, 17(3), 213-226.

Williams, K. M., Nathanson, C., \& Paulhus, D. L. (2010). Identifying and profiling scholastic cheaters: their personality, cognitive ability, and motivation. Journal of Experimental Psychology: Applied, 16(3), 293.

Zuckerman, M. (2014). Sensation seeking (psychology revivals): beyond the optimal level of arousal: Psychology Press. 